\title{
CONFLICTIVIDAD Y MODERNIDAD: una ética de mínimos para la resolución de conflictos
}

\author{
Arturo Vallejos Romero*
}

\begin{abstract}
El objetivo del presente artículo es confrontar algunas ideas que puedan ayudarnos a salvar los desacuerdos en sociedades pluralistas, conflictivas y complejas como América Latina. En específico, las ideas que serán vertidas y confrontadas en el texto iniciarán con una breve introducción, para luego exponer el pluralismo en nuestras sociedades actuales y cómo éste nos impele a buscar salidas viables para salvar nuestras diferencias. Posteriormente trataremos el tipo de consenso al que deberíamos adscribir y la opción del diálogo o pacto comunicativo para lograrlo. Tomaremos, para el apartado anterior, algunos conceptos de la Acción Comunicativa y una Ética discursiva, para luego abordar el andamiaje donde se deberían sustentar ciertos mínimos deseables para dar cuenta del disenso y/o el conflicto y la propuesta de algunos mínimos. Consecuentemente, expondremos el rol del Estado como garante del bien común, para finalmente esbozar algunas conclusiones.

PALABRAS-ClaVES: resolución de conflictos, comunicación, pluralismo, diálogo, diferenciación.
\end{abstract}

\section{INTRODUCCIÓN}

En las tres últimas décadas, la sociedad moderna ha producido y reproducido una creciente diferenciación. En su interior, las fuerzas fragmentadoras y centrífugas han propiciado que cada esfera funcional tienda cada vez más a la autonomía, se clausure operacionalmente y toque una melodía que sólo ella sabe y puede tocar. En esta nueva lógica societaria, asistimos a una pluralidad de esferas que ya no obedecen a un director, sino más bien tienden a acoplarse operativamente bajo formas flexibles y temporales, para ofrecerse sus prestaciones y, en este escenario, elaborar espacios y estrategias para dar cuenta de los conflictos que una sociedad altamente diferenciada y contingente les coloca. Esta dinámica operativa sustenta una idea de diferenciación funcional - a nivel mundial - cada vez más radical,

* Doutor em Ciências Sociais. Professor do Centro de Estudos de Desenvolvimento Local e Regional (CEDER) da Universidade de Los Lagos. Integra o Núcleo de Pesquisa Economia e Meio Ambiente do CEDER da Universidade de Los Lagos.

Lord Cochrane 1056, Osorno, Chile. avallejos@ulagos.cl; arturovallejos@yahoo.com pero que encuentra ciertos problemas cuando observamos algunas regiones del globo que, operando bajo un nicho organizativo mundializado, se estructuran bajo formas distintas.

Haciéndose cargo de lo enunciado en el párrafo anterior - a modo de confrontación - podemos decir que no todas las sociedades se podrían tachar de pluralistas o altamente fragmentadas. Sartori expone que

no podemos 'echar en un mismo saco' a sociedades con un moderno pluralismo, como por ejemplo la occidental, y ponerlas en el mismo nivel que el sistema de status jerárquico medieval, el sistema de casta hindú o la fragmentación tribal de tipo africano (Sartori, 1995, p.114-115).

Desde una perspectiva sociológica, en una sociedad modernamente diferenciada, no todas las regiones del mundo cuadran perfectamente con la idea o distinción perfecta de una diferenciación funcional a secas, sino más bien operamos bajo una sociedad mundial, pero con matices, es decir, con resabios estratificados o dinámicas concéntricas (Luhmann, 2007; Lechner, 1997; 
Mascareño, 2001, 2000). ${ }^{1}$

En esta línea - y siempre en un plano de confrontación y complementación a la idea de fondo que proponemos en los párrafos anteriores -, Sartori, al preguntarse por sociedades pluralistas, aborda el tema en tres niveles: a) el cultural (nivel de las creencias); b) el societal y c) el político. Tomando los dos primeros puntos, a) una cultura pluralista implica una mirada del mundo basada en la creencia de que la diferencia y no la semejanza, el disenso y no la unanimidad, el cambio y no la inmutabilidad, contribuyen a la buena vida (Sartori, 1995) y b) el pluralismo societal se entiende como diferente a la diferenciación social, pues, para Sartori, una sociedad compleja está diferenciada, lo que no implicaría que todas las sociedades lo estén pluralísticamente. Esta idea no dista de una interpretación sistémica, si aducimos que la modernidad puede ser distinguida en modernidades centrales y periféricas (Vallejos, 2005, 2007a, 2007b, 2008), donde, en las segundas, sus dinámicas operativas obedecerían más que a la diferenciación a la desdiferenciación, y más que al acoplamiento entre esferas, a una intervención prescriptiva y desdiferenciadora, que hace que ciertos sistemas funcionales hagan operar con sus propias lógicas a otras esferas de la sociedad (Neves, 2001, 1994, 1993; Zamorano, 2003a, 2003b), por lo tanto de manera jerárquica, menos diferenciada o menos pluralísticamente.

Las ideas que serán vertidas y confrontadas en el transcurso del texto (I) iniciarán con una breve aproximación al pluralismo en la sociedad moderna y cómo éste nos impele a buscar salidas viables para salvar nuestras diferencias. El segundo apartado (II) tratará el tipo de acuerdo o consenso al que deberíamos adscribir y la opción del diálogo para lograrlo. Tercero (III), el anclaje para el apartado anterior estará en la comunicación. El

${ }^{1}$ Una sociedad de tipo concéntrica, según Mascareño (2000), se caracteriza por tener un sistema funcional que ejerce un campo gravitacional sobre otros sistemas produciendo desdiferenciación o interrupción en las formas de operar autónoma y clausurada de los distintos sistemas funcionales de la sociedad. En América Latina, esta función (de control e intervención) la ha cumplido el Estado - como referente descriptivo del sistema político a lo largo de la historia del continente latinoamericano. cuarto (IV) punto abordará el andamiaje, como expectativa normativa, donde se deberán sustentar ciertos mínimos deseables para dar cuenta del disenso y/o el conflicto, y el quinto (V), la propuesta de algunos mínimos. El sexto (VI) punto abordará el rol del Estado en nuestras sociedades - pluralistas y conflictivas - como garante del bien común, para luego esbozar algunas conclusiones (VII) en el séptimo punto.

\section{BREVES ALCANCES SOBRE EL PLURALISMO EN LA SOCIEDAD MODERNA}

El pluralismo puede entenderse en la actualidad como aquel en que

existen diferencias significativas en las actitudes y creencias fundamentales de sus miembros, diferencias que alcanzan incluso la idea [...] de lo que debe ser un acuerdo político justo (Innerarity, 2003, p.70)

Si ponemos el acento en lo trágico de una sociedad pluralista o diferenciada por funciones, en el sentido de un escenario social agonal, que tiende con mayor fuerza a la confrontación y las diferencias, las sociedades tradicionales o aquellas que comienzan a modernizarse nos dan muy poco sustento para dar cuenta de la sociedad contemporánea. En el primer tipo de sociedades, podemos observar un pluralismo "encapsulado jerárquicamente”, donde los grupos están plena y fuertemente confinados estructuralmente y la política domina desde arriba, generando un tipo de normatividad inflexible que acepta las desigualdades (2003, p.71), es decir, que existan de manera "natural" aquellos que en la cima mandan y se incluyen, y otros abajo, que tienen que obedecer y se les excluye. Así también podemos observar un "pluralismo de las esferas", es decir, esferas de vida, de un conjunto de prácticas e instituciones organizadas de acuerdo con valores, normas particulares, y que cuando nos cambiamos de una a otra, tienden a modificarse una cantidad de expectativas (2003). Sería en los bordes de éstas donde se generarían los conflictos y se manifestarían 
dificultades a la hora de definir estos límites, pero donde cada ámbito daría un marco de acción apropiado en el que habría que mantener estos deslindes y ninguna de las esferas debiera convertirse en una posición privilegiada para dirigir y (o) actuar sobre otras. Innerarity insiste que, en este punto, se observan pocos espacios para las diferencias y significados en cada una de ellas.

Ante estas dos expresiones anteriores del pluralismo, Innerarity expone que también pudiera darse un pluralismo ilusorio como una posible salida, la cual reflejaría juicios equivocados y donde, al manifestarse desacuerdos, la estrategia sería buscar una posición correcta. En otras palabras, una mirada que daría la idea de una verdad única, unitaria, en la cual convergerían hombres sensatos y sinceros (Innerarity, 2003, p.72-73). Así también, el pluralismo y el concepto de comunidad política como oposición han tenido como finalidad superar las diferencias, o que éstas dejaran de ser fuente de disenso y (o) conflicto (Innerarity, 1997, p.11), ${ }^{2}$ pero ante una sociedad como la moderna, tal perspectiva, así como los rendimientos que pudieran hoy tener, no hacen más que quedar desfasados y permeables a cualquier crítica ante la creciente complejidad y la alta contingencia del mundo contemporáneo. Tal situación nos da más bien un resultado dramático, trágico y progresivo, pues el pluralismo agudo nace y se desarrolla cuando se persiguen fines incompatibles, cuando se tienen ideas diferentes acerca de qué debe ser una vida buena, un buen gobierno, etc.

En este escenario, si abogamos por un pluralismo que asuma una idea de comunidad política anclada en lo doméstico, cualquier intento que se quisiera emprender para dar cuenta de la conflictividad social debiera encontrar grandes

${ }^{2}$ A modo de ejemplo, y sin poder profundizar al respecto - por las características generales del texto -, podemos nombrar, en esta línea, a autores como Jean Jacques Rousseau y Carlos Marx. Del primero, con el contrato social, Innerarity sostiene que cuando la opinión individual se enfrenta a la opinión de la voluntad general, es señal inequívoca de que el individuo está en error y no hace lo que realmente quiere. En cuanto al segundo, éste trató de hacernos ver que la unidad social dejaría de ser un problema una vez que fueran superadas las divisiones de clases en la sociedad burguesa, únicas culpables de los antagonismos entre los hombres. imposibilidades de poder llegar a buen puerto. La idea de "sociedad doméstica separada de otras culturas o países se vuelve cada vez más anacrónica (Innerarity, 1997; 2006), pues esa comunidad siempre pequeña - como la polis griega - que privilegia las relaciones cara a cara, diferente a las sociedades actuales, no podría remitirse a un tamaño reducido, sino más bien debiera tomar como base una comunidad más vasta y distinta (países o regiones)" (Sartori, 1995, p.123), es decir, una sociedad mundial (Stichweh, 2000). Es en este contexto donde se expresan problemas, conflictos y situaciones críticas, los cuales pueden ser graficados en ámbitos como el medioambiental, económico, en las migraciones, entre otros, hay fenómenos que sobrepasan las fronteras administrativas del Estado-Nación y que, bajo la dinámica mundial, nos mueven a un permanente aprendizaje y a manejarnos cuando la sociedad se estructura operativamente bajo formas diversas de expresión o autodescripciones que de ella se hagan en su interior. Por lo tanto, el mundo actual nos enfrenta a vivir con esta diversidad - global como local, con una alta complejidad, tremendamente inestable y que nos desafía a poder sobrellevar nuestros conflictos.

Por otro lado, poca plausibilidad - teórica como práctica - tendría creer en la posibilidad de llegar a un equilibrio armónico o a una cierta neutralidad. Esta perspectiva nos presenta la posibilidad de conducirnos, en materia moral y política, en una dirección que difícilmente nos pudiera llevar enfrentarnos a conflictos o a situaciones que pudiéramos experimentar como una imposición. En este contexto, y como someramente lo mencionamos más arriba, el contrato social ha sido el modelo en que se han hecho valer ciertos procedimientos cuya neutralidad habría de garantizar la aceptabilidad universal de sus resultados para superar la discrepancia. Sin embargo, "el contrato social es una idealización, pues todo proceso real de discusión y acuerdo puede ser distorsionado por cualquier pequeño desequilibrio de poder, ignorancia, desatención, irracionalidad, etc.” (Innerarity, 1997, p.14-18). En 
otras palabras, para dar cuenta de nuestros conflictos, nos encontramos con que el pluralismo y (o) la diferenciación funcional nos ha traído un vació de racionalidad; donde ya no tenemos un actor en la cúspide, acompañado de un modelo, que, legitimado y valorado por todos, pueda dirimir y zanjar nuestras diferencias. La sociedad actual no permite un control de este tipo, por lo que desecha toda idea de normatividad desde un centro que pueda otorgar y legitimar una intervención que todas las esferas y actores de la sociedad mundial acepten a cabalidad.

La sociedad moderna y su régimen político: la democracia, si es observada en clave tradicional, no estaría siendo un sistema de gobierno para sociedades complejas (Willke, 2006) que tienda a calmar las diferencias. Aunque ésta nos enseñe a respetarlas y a dejar que se hagan valer, nos enfrenta a inquietudes y muchas veces a visiones desagradables y carentes de estabilidades y acuerdos seguros y duraderos. En esta línea no se propone la idea de tolerar al otro, sino respetarlo, aceptando la diversidad, la pluralidad y la complejidad que esto lleva consigo, con lo cual podamos ir más allá y valorar el enriquecimiento que supone encontrar el acuerdo, colaboración e incluso la resistencia de los otros a la hora de tratar de hacer valer nuestros intereses y aspiraciones (Cortina, 1994).

Nuestra historia, especialmente en territorios periféricos como nuestros países, ha estado marcada por una continua dinámica de ejercer el control de la sociedad desde un centro político, rol que le ha tocado al Estado como organización del sistema político y cuya empresa constantemente se ha encontrado con problemas y limitaciones para llevar a cabo esta tarea. Aunque el pluralismo nos es adverso y nos limite o ponga dificultades para alcanzar mecanismos de acuerdos, no podemos quedarnos ajenos a tematizar las contradicciones y conflictos y tratar de reducirlos. Es decir, aunque nos encontramos frente a una democracia de tipo Agonal (Innerarity, 1997, p.21; Martínez, 2000, p.64), un escenario de competencia, de combate abierto, con resulta- dos imprevisibles y equilibrios precarios, tan lejos de la estabilidad consensual como del equilibrio, tal escenario nos lleva a aceptar la contingencia de nuestras propias construcciones, el anclaje histórico de los principios que regulan nuestra vida en común y el formato en que viene la sociedad actual: la diferenciación funcional. Se trata de reconocer la historicidad y contingencia de nuestro vivir y aprender a desenvolvernos en contextos precarios que nos impone una sociedad moderna.

\section{LOS ACUERDOS SUSTENTADOS ENEL DIÁLOGO}

El cómo poder dar solución o transformar los conflictos en una sociedad pluralista, como cuestionamiento y problema relevante, pasa por entender que hay que abocarnos a acuerdos austeros y precarios. Aunque estos, según lo expresado, resultan con grandes probabilidades en la práctica de no ser alcanzados, y sabiendo que las incompatibilidades no se superan apelando al ideal de unidad, se hace relevante saber qué tipo de acuerdo se requiere al ver que el consenso total se torna inalcanzable.

Aunque de fondo no adherimos a la propuesta de Adela Cortina, esta autora nos presenta

... dos modos de entender el consenso: como pacto estratégico de individuos que establecen entre sí una relación de sujeto a objeto y se contemplan mutuamente como medios para sus fines, o como mutuo entendimiento entre individuos que establecen entre sí una relación de sujeto a sujeto y se contemplan recíprocamente como fines en sí, como absolutamente valiosos y sujetos de derechos. Frente al pacto estratégico, el segundo consenso se entiende como concordia (Cortina, 1986, p.174).

En este proceso de construcción de acuerdos y fortalecimiento de una democracia que tenga como fundamento la participación, debiera potenciarse una acción que tenga como sustento a la comunicación, ejemplificada en el segundo modo expuesto por Cortina, pues estaría anclada en estructuras que llevarían a aportar al entendimiento y la superación de los conflictos. 
Lo anterior, como una idea relajada de un proceso o "pacto comunicativo como Acción Social por Comunicación” (Hoyos, s/f, p.8), busca los acuerdos compartidos y el afán de encontrar la mejor alternativa que beneficie a las partes, propiciando la posibilidad de llegar a ser convencidos. Esto no tiene como finalidad una lógica impositiva, sino más bien de seducción o persuasión, es decir, como una estrategia que invite a que el propio actor acepte e inicie su propia transformación, para llegar, como expone Cortina, a un entendimiento mutuo, una comprensión compartida, a posibilidades de acuerdos libres y concertados que imprimirían mayor convicción y fuerza a las diversas acciones sociales (Cortina, 1994, p.8-9).

Como lo hemos planteado, esto supone una actitud de diálogo, donde se debe estar dispuesto a persuadir y poner en el radio de detección del que se quiere transformar, lo que se quiere entregar. En otras palabras, una selección (información) que tenga como pretensión ser aceptada por Alter y así llegar a un acuerdo y solucionar el impasse. Independiente de motivos y argumentaciones, que si los hay y surgen los efectos deseados ibienvenidos sean!, se quiere que Alter acepte la comunicación que Ego pone en su radar, para que comience la transformación y superación de la contradicción. De fondo, aunque no sea la finalidad última, esto debiera traducirse en motivos y argumentos que convenzan a quienes defienden otras posiciones, bajo mínimos como el respeto y reconocimiento de las opiniones y argumentaciones del Otro, que enriquecen las perspectivas propias y que, por extensión, debiera abrirnos a otras perspectivas - a la creación. Esto nos permitiría que, en la destrabazón de los conflictos, los actores pudieran seguir haciendo lo que tienen que hacer; potenciaran y fortalecieran las relaciones sociales, así como los procesos comunitarios y sociales en una sociedad plural que le cuesta ponerse de de acuerdo. Una construcción que, a través de procesos comunicativos, tienda, a través del dialogo y el entendimiento, a superar la improbabilidad de la comunicación - como el consenso - no sólo puede aportar a reducir los disensos y (o) conflictos, sino que precisamente orientar de forma especial a incluir a la comunidad y dotar de recursos de participación democrática.

\section{LA COMUNICACIÓN COMO MEDIO PARA LA RESOLUCIÓN DE CONFLICTOS}

La dinámica de la sociedad actual, pluralista y por tanto conflictiva, no nos permite abogar por normas últimas que sirvan como referentes trascendentales para salvar las diferencias. Ante esta aseveración, ya desplegada en los párrafos anteriores, queremos introducir una distinción que nos puede ayudar a sustentar la propuesta de una ética de mínimos - soporte para cualquier mesa o sistema de deliberación -, sabiendo que no hay valores últimos ni posibilidades de consensos finales que sirvan y sean posibles en la sociedad actual. Esta distinción es la siguiente: expectativas normativas y expectativas cognitivas. Cuando hablamos de expectativas nos referimos a "estructuras comunicativas altamente consistentes de selectividad futura, que por su consistencia, reducen las posibilidades de variación de las comunicaciones.” (Luhmann, 1996, p.102, apud Mascareño y Mereminskaya, 2005, p.32), las que reducen la contingencia, y que siendo compartidas en determinados contextos, probabilizan tipos de selecciones definidas y no otras. Para nuestro caso, si queremos llegar a ciertos acuerdos en algún conflicto, estas expectativas se encargarían de hacer posibles las comunicaciones que tengan como finalidad ciertos acuerdos y cerrar todo tipo de posibilidad a otras que no tengan esa finalidad. Ahora, esto no es infalible, es decir, que las expectativas estabilizadas no fallen, pues a cada momento observamos que muchos intentos de salvar problemas y conflictos a través de negociaciones no llegan a buen término, por lo que se necesitarían mecanismos independientes que pudieran elevar las probabilidades de sustentar espacios deliberativos y acuerdos para el futuro.

En este caso, podemos utilizar la distinción más arriba expuesta, donde, si hay decepción al 
no cumplirse lo que esperábamos, se aprende de ésta y se buscan equivalentes o acomodos que puedan dar lugar a su cumplimiento (expectativas cognitivas). En cuanto a las normativas, Mascareño dice que "es posible modular la expectativa en el presente resdescribiendo el modo en que se formuló en el pasado para de esa forma adaptar el pasado a la nueva situación” (2005, p.33). Por lo tanto, hay expectativas que se pueden dejar de lado y optar por otras (cognitivas), o mantenerse a pesar de que las cosas no funcionen, por lo que estabilizadas, a pesar de la decepción, la comunicación supondría mantenerlas aún cuando los hechos digan u operen en un sentido totalmente distinto.

En esta distinción estarían insertos los sistemas de la ciencia (cognitivas) y el derecho (normativas), donde las primeras estarían basadas en el conocimiento constantemente reactualizable y la segunda basada en normas que, generalmente, por la operatividad del mundo actual, son constantemente defraudadas, pero que no limitan la posibilidad de idear ciertos mecanismos que las aseguren para dar cuenta de defraudamientos constantes. Por lo tanto, sabiendo que, en ambos casos, no hay esencias y su dinámica proviene de la praxis, nos parece interesante la aguda observación que realiza Mascareño al tomar a Habermas que, al observar el problema desde el lado cognitvo, las expectativas normativas serían expectativas cognitivas que han sido fijadas y que no muestran voluntad de aprender o que no manejan la distinción para observar que las cosas son de otro modo, por lo que no habría indisposición a aprender en el afectado, pues tal disposición sólo podría ser calificada por un observador de segundo orden como normativa (Cfr. 2005, p.34).

Ahora, ante los riesgos que implica lo anteriomente dicho, es que existe un sistema como el Derecho, cuya función está en asegurar y establecer condiciones para que se den estas expectativas normativas. El problema que observamos es que muchas de las contradicciones y (o) conflictos que hoy día se producen y se reproducen en la sociedad, son de un nuevo calado y el Derecho no ha logrado dar cuenta de ellos, pues no ha in- corporado en sus programas los nuevos temas y problemas (medio ambiente, Internet, deportes, etc.), operando de manera más lenta a como lo hace la sociedad. Por el otro lado, los problemas que se le presentan difícilmente los puede incorporar, pues se encuentran en su entorno de sus rendimientos, siendo otros sistemas funcionales quienes tendrían que dar cuenta de ellos. En otras palabras, estas expectativas normativas y cognitivas no encuentran una unidad o referente único de donde puedan emanar las orientaciones para sentar mínimas bases que funjan como plataforma para enfrentar la conflictividad social.

En este contexto, lo que una sociedad moderna nos puede permitir es buscar aquellos criterios mínimos (normas) que podamos compartir y nos sirvan de norte para una práctica que impregne la actividad social. En esta idea, al igual que los autores trabajados - que se anclan en una corriente sistémica -, encontramos la teoría de la acción comunicativa desarrollada por Jürgen Habermas y Karl Otto Apel, cuyo fundamento está en el consenso y en el reconocimiento universal de los derechos de interlocución. Esta ética discursiva entiende la racionalidad ligada a las condiciones de posibilidad de comprensión, comunicación, cooperación solidaria y acuerdos universales con todos los seres humanos, desde la responsabilidad de aprender de otras culturas y de asumir críticamente nuestra occidentalidad.

Al igual que con Adela Cortina, no adherimos a las ideas de fondo de la teoría propuesta por los autores más arriba mencionados, sino que tomamos los conceptos de comunicación y cooperación para desarrollar lo que de fondo propone este artículo. Pero, a modo de irritación, cabe preguntarse e interrogar a esta perspectiva si es posible que más de 6 mil millones de personas puedan aunar criterios y llegar a consenso sobre, por ejemplo, los mecanismos - teóricos como prácticos - para dar cuenta de la crisis ambiental. Este intento tiene muchas más posibilidades de fracaso que de éxito. El pluralismo conflictivo en una sociedad con una alta diferenciación funcional, como lo hemos planteado, 
hace improbable acuerdos universales o una unidad universal, por lo que diferimos a la hora de lograr tales arreglos. Las soluciones tendrán como objetivo salvar el impasse y lograr acuerdos mesurados y limitados, donde la operatividad social no se atrofie y se pueda con ello no afectar la calidad de vida de las partes involucradas en los conflictos regionales o locales.

Pese a lo anterior, hay algunos puntos en la teoría mencionada que vamos a tomar y moderar en el intento de dar cuenta de la conflictividad social. Aunque sean expuestos tal como la teoría crítica los enuncia, dejo en aviso que los utilizaremos acomodativamente en la empresa que esta comunicación pretende describir.

Los puntos principales de esta propuesta de ética discursiva ${ }^{3}$ tienen que ver, primero, con ir más allá de lo cotidiano de los individuos, es decir, apuntar a los niveles de interacción, donde se dan unas posibilidades de comunicación. Así, cuando cada uno habla, trata de darse a entender, de decir alguna verdad (o mentira), ser sincero (o no), entre otras cosas (Martínez, 1995, p.213; Fisas, 2001, p.339-342). Donde, a través de lo que desea decir (selección), establece un forma de comunicación (cómo lo va a decir) que de regreso a Alter, éste, a través de un sí o un no en la comunicación, dirá si comprende o no comprende lo que fue seleccionado para él (comprensión).

Un segundo punto hace referencia a "los derechos de interlocución para todos los seres humanos" (Habermas, 2000, p.78-79). ${ }^{4}$ Así, como tercer punto, para entendernos y desarrollar o hacer probable la comunicación, hemos de realizar un aprendizaje de nuestras perspectivas e interesarnos

${ }^{3}$ La idea fuerza de esta ética del discurso, según el texto citado de Habermas, es que, en virtud de sus propiedades pragmáticas, los discursos permiten una formación de la voluntad guiada por el conocimiento y de tal tipo que los intereses de todos y cada uno de los individuos particulares pueden desplegarse sin por ello romper el vínculo social que ata, en primer término, a cada uno con todos. En tanto que participante en discursos prácticos, cada uno ha de valerse por sí mismo, y sin embargo permanece inserto en un contexto objetivamente universal.

${ }^{4}$ Este principio se fortalece con la aseveración de Habermas al proponer que cada participante particular en la argumentación sigue siendo con un "si" y "no" la última instancia; no puede dejar que nadie le represente en el rol de quien toma postura ante pretensiones de validez criticables. por la de los otros participantes (en el caso que tengan sentido, por lo tanto resonancia y no solamente ruido). Este punto es interesante al plantear la autonomía, clausura e insensibilidad que las esferas funcionales de la sociedad han desarrollado en la actualidad, por que ciertos acoplamientos operativos (mesas de deliberación) pudieran darnos la posibilidad de gatillar espacios de encuentro que, inducidamente, nos permitan observar, en nuestro radar, los intereses explícitos de los Otros. Lo importante es que lo que nos digan los demás pueda tener la misma pretensión de validez que lo que exponemos nosotros (Cortina, 1986). ${ }^{5}$

Un cuarto punto dice relación con la responsabilidad que todos debiéramos asumir, la cual deriva del descubrimiento de la autonomía, para, en un quinto y último punto, pretender realizar una ligazón cooperativa y solidaria con el resto de los actores que participan, dando pie a que se exija actuar en consecuencia, generando un trasfondo para que la responsabilidad no sea sólo para otros, sino autoinclusiva.

Con esto queremos decir que la propuesta de la Ética Discursiva no es ninguna fórmula mágica para llegar a la paz o al buen vivir, ni puede arrogarse la pretensión de solucionar los conflictos o la hostilidad entre los individuos o las naciones. La teoría propuesta por Jurgen Habermas y Otto Apel debe ser tomada como un pool de orientaciones y criterios que pueden servirnos de guía, pero que no nos enseñan la solución correcta y que el consenso sea ejemplo o sinónimo de unidad (pues si hay consenso hay disenso ${ }^{6}$ ), sino la manera de buscarla. Son patrones que se pueden asir, no inge-

${ }^{5}$ Adela Cortina refuerza este principio al decir que "En definitiva, los individuos nos percataríamos de que, aun cuando en nada comulgáramos, la vida en sociedad, regulada por normas consensuadas, nos proporciona más ventajas que el robinsonismo, y de esta necesidad de supervivencia pacífica y provechosa, sacaríamos - cual conejo de chistera - las virtudes que adornan la moral cívica: tolerancia, disponibilidad para el diálogo y para aceptar lo consensuado a través de él, rechazo de toda pretensión de poseer el monopolio de la verdad." (Cortina, 1986, p.153).

${ }^{6}$ Hacemos esta aseveración, pues, para que un concepto sea viable técnicamente, en una propuesta de intervención que tenga sustento teórico, debe tener dos lados. Es decir, debe ser una forma, que cuando indicamos un lado, nos de, aunque observado por el "rabillo del ojo", por el solo hecho de observar, el otro lado. 
nuamente, ante una sociedad compleja, plural y conflictiva. Las propuestas de la teoría de la acción comunicativa debieran ser tomadas como una invitación a practicar una forma que nos permita entender y transformar positivamente los conflictos, a través de colocarnos en el lugar del otro y deliberar en espacios democráticos donde los actores sean reconocidos como interlocutores válidos.

Estos criterios, que se enmarcan en un contexto de sociedad mundial y diferenciada, pueden servirnos para visualizar algunos mínimos deseables que podrían sustentar formas que nos permitan juntarnos a negociar y consensuar, de manera colaborativa, salidas a los conflictos que hoy aquejan a nuestros territorios.

\section{ALGUNOS CRITERIOS PARA SUSTENTAR UNOS MÍNIMOS ÉTICOS}

En la actualidad, los conflictos de carácter regional o local tienen repercusiones globales, (guerras, recursos naturales, etc.). Son variados los intelectuales que buscan crear una comunidad internacional, global o planetaria, para encontrar una ética, por lo general de máximos (normas, valores universales.) que sean esenciales para sustentar una vida digna, pero no sin conflictos (Fisas, 2001, p.323), intento que encuentra poca plausibilidad en la actualidad (Teubner, 2005). Esta idea tiene sus bases en las posibilidades que cualquier desastre repercuta de manera grave en el planeta, por lo que el objetivo es generar una ética, unas reglas del juego que vinculen a todas las personas y que permitan desterrar externalidades negativas que denigran a la persona y a la sociedad.

Hay una serie de variables que intervienen es pos de esta búsqueda de valores o normas para sustentar el buen vivir. No podemos dejar de lado que el creciente aceleramiento mundial, cuyos comienzos estuvieron circunscritos en la década del 80 del siglo pasado y que ha dejado el mundo en nuestras manos (globalización de la cultura, de la información, la tecnología, las finanzas, la economía, entre otros), a hecho que se refuercen las identidad locales, lo que nos lleva a observar un aumento de la solidaridad entre sus miembros, pero que también, paradojalmente, nos lleva a no aceptar la diversidad. Ante la explosión de movimientos nacionalistas, proclamaciones de nuevas identidades, demandas de reconocimiento de nuevos derechos étnicos o comunitarios y afirmaciones de diversidad (Taylor, 1993), es preciso ser cautos y prudentes en cuanto a la viabilidad inmediata de acordar los valores que podrían ser aceptados universalmente. Por lo tanto, la idea es poner el énfasis en valores mínimos que puedan operar en territorios y (o) comunidades particulares históricamente acotados. Habría que trabajar la idea de que vivimos juntos y hacemos juntos, donde esta idea del bien en común tiene como existencia al Otro y, para que éste exista, se requiere de un sistema de valores mínimos a los cuales podamos, en momentos difíciles, echar mano.

Mirar de esta forma la construcción de nuestros espacios, especialmente Latinoamérica, supone entender esta complejidad, diferenciación y pluralismo, y así, de una forma dialógica, acor$\operatorname{dar}^{7}$ algo como un código de conducta. Esta sería una ética de la corresponsabilidad, que debería tener en cuenta lo que hacemos hacia nosotros y hacia las futuras generaciones y que implicaría valores mínimos que podamos compartir y defender, siendo de relevancia que estas corresponsabilidades puedan ser traducidas en normas que pudiéramos tener en nuestro horizonte de expectativas.

Una propuesta y establecimiento de mínimos deseables para salvar nuestros disensos y (o) conflictos, a parte de una gran tarea, es una empresa de considerable dificultad. ${ }^{8}$ Lo que se

7 Cortina corrobora esta idea diciendo que el diálogo y el consenso, como procedimientos legitimadores de normas en la vida ciudadana, requieren como trasfondo una vida dialogal y consensual, que intente pertrechar a todos los posibles interlocutores de medios materiales, culturales e informativos necesarios para dialogar en pie de igualdad y con ciertas garantías de competencia.

${ }^{8}$ Una de las dificultades estriba en que un pacto de mínimos, sellado en condiciones de deformación, desigualdad y coacción, no pasa de constituir un provisional equilibrio de intereses deformados que mal puede constituir una fuente legitimadora de la moral. De ahí que las famosas éticas del diálogo propongan, como condición trascendental de racionalidad de los pactos, las reglas de una situación ideal de habla o de argumentación, que sirven como principio regulativo de los acuerdos fácticos. 
expondrá es el andamiaje para algunos mínimos posibles que debieran servir como sustento al propósito de querer dar solución a los disensos y (o) conflictos que se presentan. Podrán no tener éstos soluciones profundas, es decir, dar cuenta de la raíz del problema - que sería lo óptimo -, pero sí acuerdos que faciliten la reproducción de la dinámica de los distintos actores involucrados. Esto no quita que los protagonistas sigan dialogando en busca de nuevas formas de salvar sus diferencias sustentadas en estos mínimos.

En esta empresa, una de las tantas dificultades estriba en que palabras y conceptos no tienen los mismos significados para las personas y las sociedades, siendo muy difícil ver cuál es el punto neutro desde el cual pudieran desarrollarse. La tarea debiera estar por encontrar las similitudes de principios y reglas de la sociedad Latinoamericana. Para ello debiéramos tener como plataforma ciertos principios.

Debiera darse un principio de Participación y Decisión, pues el hacer aplicable esta ética supondría empoderar e incluir a las comunidades locales dándoles la posibilidad de deliberar y decidir sobre sus propios problemas y condiciones de vida, haciéndolos constructores y participantes en sus proyectos de vida. Un segundo principio o regla del juego sería hacer nuestra la máxima "que lo que no quieres para ti no se lo des o hagas a los demás", es decir, Reciprocidad, donde el que tenemos al frente, el Otro, es un interlocutor tan digno y valioso que se debe respetar y valorar. Tercero, un concepto ya comentado, la Responsabilidad, que debería plasmarse en un principio inclusivo, de Corresponsabilidad, lo que debiera traer como consecuencia el asumir nuestras acciones, tanto a nivel individual como colectivo. Un cuarto principio, el cual tendría varias aristas, tiene que ver con La Satisfacción de Necesidades Básicas, principio que debe anclarse en los mínimos sustentos para la persona y asumir la responsabilidad de observar la vulnerabilidad humana, cooperar para aliviar el sufrimiento de los demás y proteger sus derechos.

En esta base se sustentaría cualquier tipo de mínimos deseables y posibles para poder salvar de buena forma los conflictos que son parte de nuestra sociedad y que se nos hace patente día a día.

\section{MÍNIMOS ÉTICOS COMO ANDAMIAJE PARA LA CONSTRUCCIÓN DE ACUERDOS}

Son estos principios, expuestos en el apartado anterior, los que deberían sustentar una ética de mínimos. Mínimos que tendrían que apuntar a la justicia, cuyo fin sería justificar las condiciones mínimas necesarias para una convivencia que tenga espacios para salvar sus desacuerdos. Ahora, en una sociedad pluralista, basada en la oposición recurrente, existen ciudadanos que ya comparten ciertos mínimos, que, según Adela Cortina, "les permiten tener una base en común para ir construyendo desde ellos, responsablemente y seriamente su mundo" (Cortina, 1993, p.103).

Una propuesta de mínimos debiera tener ciertas características, como el respeto a unos derechos, el aprecio a unos valores y la estima de una actitud dialógica, los cuales son compartidos en sociedades como la nuestra que suscriben a una democracia liberal. Por eso, no se trata de ver cómo los acordamos, sino de "descubrir" aquello que ya hemos aceptado en nuestra vida cotidiana (normativamente). Por lo tanto "éstos serán la condición para cualquier tipo de acuerdo en una sociedad plural y democrática” (1993, p.103-104).

Estos mínimos se sustentan (concretan) y están implícitos en los Derechos Humanos, es decir, en el respeto a los derechos de primera, segunda y tercera generación, que son el acatamiento de valores como la libertad, la igualdad, la solidaridad y la actitud dialógica, con lo cual será posible el poder entenderse con el Otro.

Adela Cortina (p.105) nos expone de forma clara que los derechos de primera generación son los civiles y políticos, el derecho a la vida, al pensar y expresarse libremente, a reunirse con quienes uno desee, a desplazarse por donde uno lo estime oportuno y a participar en la legislación de su propia comunidad política, siendo la piedra angular de un 
estado de derecho y de una sociedad abierta.

Los derechos de segunda generación derechos económicos, sociales y culturales - son el apoyo a las libertades de un Estado que está obligado a hacer justicia, pues, sin alimentación suficiente, sin casa y abrigo, sin medios para acceder a la cultura, su protección ante la enfermedad, la ancianidad, la jubilación o el desempleo, sería ilusorio decir a una persona que es libre. En este punto, es necesario hacer hincapié que pensar en hacer justicia o dar cuenta de los problemas que emanan de la sociedad sea una tarea solamente para el Estado, como proveedor de lo que los actores y sistemas de la sociedad requieren, es caer en un error. Pensamos que el Estado, punto que detallamos más adelante, debiera accionar como coordinador y (o) supervisor para con aquellos sistemas funcionales que tienen funciones como dar cuenta de la escasez de recursos (Economía), de que es verdad y no lo es (Ciencia), de la formación (Educación) y de velar de dar cuenta a habilidad de su propia función: producir decisiones vinculantes. En otras palabras, resguardar que estos sistemas y sus organizaciones den cuenta de los problemas que la sociedad produce y reproduce.

Los derechos de tercera generación no han sido objeto de una declaración internacional, pero están presentes en la cotidianeidad social, apuntando a lo esencial de la vida humana, como es el nacer y vivir en un medio ambiente sano, no contaminado de polución y de ruido, y el derecho a vivir en una sociedad en paz. Si hay respeto de estos, se darán por asumidos todos los anteriores.

Por lo tanto, en una sociedad democrática, los valores mínimos compartidos son: la Libertad, anclada en la independencia de la persona con el Estado como con sus pares, la posibilidad de participar en las decisiones con respecto a las leyes vigentes de su comunidad política (1993, p.108), y la Igualdad, como ausencia de dominación.

Importantes organismos internacionales

9rganismo como La Comisión de Gestión de los Asuntos Públicos Mundiales y La Comisión Mundial de Cultura y Desarrollo de la UNESCO. han expuesto ciertos mínimos deseables que debieran existir para una vida digna en el planeta. Mínimos que comparten estas instituciones son la Justicia, La Solidaridad, Respeto a la Vida y el Medio Ambiente y la Responsabilidad. Todos éstos sustentados en el diálogo y de ver en cada actor social un interlocutor válido. Esta tendencia visualiza cierta coincidencia entre los organismos e intelectuales que se enuncian, que vislumbran ciertos mínimos que son relevantes a la hora de establecer acuerdos mínimos ante cualquier problema o conflicto.

\section{ELESTADO COMO GATILLADOR DE ESPACIOS DEMOCRÁTICOS}

Los disensos y (o) conflictos son fenómenos reales y autoproducidos por las operaciones sociales de una sociedad compleja y conflictiva. En este tipo de sociedad, éstos han llegado para quedarse y tendremos que aprender a enfrentarlos. Por lo tanto, en su resolución, deberán tener parte los actores individuales o corporativos que den inicio a las incompatibilidades de intereses o valores y se encuentren tocados por las externalidades que estos producen, los cuales tendrán que buscar las mejores formas para salvar satisfactoriamente este tipo de confrontaciones.

La conformación de América Latina, como lo enunciábamos en el primer apartado, obedece a una dinámica que tiende a estructurarse con resabios estratificados o jerárquicos. Las fuerzas desdiferenciadoras de sistemas como la economía y la política prevalecen en nuestras sociedades y opacan (intrasparentan o cooptan) al resto de las esferas sociales y organizaciones sociales, es decir, éstas últimas tienden a ser colonizadas y a operar en clave de las lógicas del sistema económico o político. En este contexto, la región, desde su conformación, obedece a un patrón distinto que las sociedades desarrolladas. En América Latina, el Estado se conformó antes que la sociedad, por lo que toda demanda la procesaba y sigue procesando la burocracia gubernamental. Así, todo conflicto que 
hoy se manifieste tiende a centralizarse, es decir, a ser resuelto en los centros de poder.

$\mathrm{Al}$ estar ante sociedades complejas, pues América Latina no escapa a este diagnóstico, el Estado se ve sobrepasado por la complejidad y no puede responder a la elevada contingencia que la sociedad genera, así como a los procesos conflictivos que se desencadenan. Por las características de tipo estructural u operativa de una modernidad periférica como América Latina, los problemas y conflictos tienden a ser resueltos por aquellos sistemas que ejercen una mayor fuerza gravitacional en la sociedad (política o economía), generando los desencuentros, disensos y conflictos cuando la intervención se ve teñida por elementos que, más que ayudar que las esferas sociales se autorregulen en sus propios términos, los desdiferencian y anulan. Es sabido que el mercado no funciona con una lógica de índole social ni la política con códigos económicos, sino que sus medios de comunicación son el dinero, la rentabilidad a corto plazo y el poder, así como distinta es la dinámica de operatividad de la sociedad civil y el medio ambiente, ${ }^{10}$ pero la intervención sigue siendo ciega a esta evidencia. Lo que prevalece en la acción para dar cuenta de la conflictividad social no es más que una intervención de primer orden, donde el que interviene lo hace desde su propia lógica de operación y no una intervención de segundo orden o reflexiva.

Si las disputas son manejadas como actualmente se hacen, las contradicciones seguirán agudizándose, ya que su solución en el centro (gobierno) hace que éstos se agraven, pues, a modo de ejemplo, en la práctica, los proyectos que implementan los Estados están sustentados en la búsqueda del desarrollo económico, y las posibles salidas ante cualquier contradicción o conflicto son manejadas en clave económica, dejando de lado a las racionalidades de los colectivos afectados. Es decir, unos ganan y otros pierden.

${ }^{10}$ El medio ambiente no cumple otro rol que no sea el irritar a los sistemas o actores, tanto personales como corporativos. El medio ambiente no se comunica para decir que le falta o le sobra algo, sino que es parte del entorno de la sociedad.
Pero ante esta situación, cabe preguntarse: ¿Quién se hace cargo de implementar estos nuevos espacios, si no tenemos una sociedad moderna ni una diferenciación funcional como en el centro de la modernidad? Este nuevo rol debiera estar en el Estado, aunque no de forma exclusiva. El siglo XXI llama a que el sistema político y su referente descriptivo, el Estado, ceda su rol central que lo ha caracterizado desde la segunda mitad del siglo XX, es decir, un Estado planificador de la sociedad, pero que se ha visto carente de dar solución a los problemas y conflictos sociales. El Estado, como actor relevante y con su peso en el imaginario social Latinoamericano, está encargado de velar por la calidad de vida de las personas como de coordinar en beneficio de ellas. Por lo tanto, el viraje debe estar en el propiciar formas donde su competencia sea el coordinar, supervisar, facilitar, mediar o catalizar nuevas posibilidades, es decir, de funcionar en sintonía de una "Governanza Moderna". ${ }^{11}$

En la actualidad, los proyectos que el Estado propone son constantemente resistidos por la sociedad, por lo que la racionalidad implícita que tiende al bien común se ve rechazada al atentar contra sus espacios de vida. Así, las externalidades, negativas como positivas, peligrosas o exitosas, no pueden ser nunca distribuidas con justicia, concretándose formas estabilizadas en la sociedad para dar cuenta de los conflictos sociales: los informes técnicos de expertos, así como la discusión a través de medios de opinión pública y la justicia. Por lo tanto, debiera propiciarse un viraje en la manera de incidir en los disensos y (o) conflictos que no estén basados en una racionalidad con apego a fines. Para lo anterior, se hace necesario: a) desmonopolizar la función de los expertos, pues no puede cerrarse la participación a ciertos grupos, sino que tiene que ser un proceso abierto por

${ }^{11}$ Esta significa, según Rodhes y Mayntz, una forma de gobernar cooperativa, diferente del antiguo modelo jerárquico, en el que las autoridades estatales ejercían un poder soberano sobre los grupos y ciudadanos que constituían la sociedad civil. En la gobernanza moderna, las instituciones estatales y no estatales, los actores na, las instituciones estatales y no estatales, los actores
públicos y privados, participan y a menudo cooperan en la formulación y la aplicación de políticas públicas. 
la relevancia social de la problemática ambiental y así propiciar nuevos espacios de formalidad a los estabilizados por el derecho; b) tener en claro que las decisiones no han sido aún tomadas, por lo que se debe abrir la estructura de toma de decisiones; c) existir un diálogo abierto entre los actores involucrados de la sociedad y no acordar decisiones a puertas cerradas entre expertos y actores políticos (Beck, 1999, p.164-165). De ahí la importancia de espacios participativos y ciertos mínimos que sirvan de andamiaje básico para proporcionar salidas que cumplan lo antes mencionado, pero que tampoco sean vistas como maquinas de producciones de consenso.

Por esto la importancia de aproximaciones que tiendan a hacer prevalecer ciertos mínimos y mecanismos de deliberación que estén sustentados en la participación, el dialogo y la colaboración, pero que tampoco sean vistas como maquinas de producciones de consenso, pues, como lo expresa Daniel Innerarity, en la modernidad actual, no se pueden eliminar los conflictos, ni los peligros incontrolados de la expansión industrial como lo manifiesta Ulrich Beck.

Las observaciones planteadas nos proponen buscar acuerdos que compatibilicen, de la mejor forma posible, los intereses de los actores involucrados, por medio de procesos de diálogo formal, democrático y participativo, y donde se preste especial atención a los intereses y aspiraciones de las poblaciones directamente afectadas. Los procesos y mecanismos propuestos deberán estar basados en la colaboración y el consenso, como también en el sustento esencial de ciertos mínimos deseables, donde los actores estarían en el centro. Estos mínimos deseables (ética de mínimos) le darían a la persona o actores locales la responsabilidad de hacerse cargo del lugar donde viven, de responsabilizarlo de lo que puede hacer con su medio natural como construido. Por lo tanto, en la minimización de la tensión de la situación conflictiva de la sociedad, los disensos y (o) conflictos deben ser vistos como coyunturas positivas; como cajas de resonancia que sirvan de instrumento de coordinación entre los actores (pri- vados y públicos). Entonces, la concertación de actores en pos de salvar los desacuerdos puede llevar a consensuar miradas de largo alcance, pero teniendo claro que, por la conflictividad social, estos acuerdos serán frágiles y de corto duración, por lo que tendrán que potenciar los espacios y mecanismos participativos y deliberativos que puedan ayudar para dar cuenta de los conflictos.

\section{UNA BREVE RECAPITULACIÓN}

Si se pudiera concluir en un tema tan complejo y que genera grandes dificultades para ser abordado, quedaría sólo decir que un pluralismo, a veces trágico, lleva a plantear la necesidad de proyectarse ante una sociedad cada vez más enraizada en una dinámica conflictiva y asumir la conflictividad social como potencial de desarrollo y no como entorpecedor, suponiendo juicios incompatibles que no se pueden tratar y que llevarían a compromisos molestos. Las sociedades diferenciadas y pluralistas no se caracterizan por su unidad, sino por su dispersión, por lo que deberemos tender a negociar cada día los desacuerdos y ofrecer espacios democráticos a la ciudadanía para su inclusión y responsabilidad ante nuestros pactos.

En este contexto, la posibilidad de la neutralidad es imposible que exista, es decir, en el sentido que ésta estaría anclada en una posición que pueda dirigir nuestras vidas en materia moral y política, donde nunca tuviéramos que enfrentarnos a conflictos. Por lo tanto, el problema de cómo mantener una comunidad inclusiva y democrática debería tener como plataforma una clara comprensión de las limitaciones que tiene un proyecto armonizador en una sociedad diferenciada como la moderna. La idea de fondo será ir adhiriéndonos a un modelo de decisiones sociales anclado en un proceso abierto de discusión y sustentado en sistemas de deliberación.

Así, el pluralismo se nos puede presentar poco amigable, donde las dificultades aparecen y se hace poco probable que la deliberación demo- 
crática pueda alcanzar un acuerdo universal, pero renunciar a lograrlo sería una falta de responsabilidad. Por consiguiente, según lo expuesto, tendríamos una Democracia Agonal, que se reclama con un pluralismo trágico, al compartir la idea de poder alcanzar acuerdos, pero sin deslegitimar el desacuerdo.

Si adherimos a una ética de mínimos que privilegie la comunicación, los conflictos no sólo tenderán a resolverse mediante acuerdos participativos en una sociedad compleja y pluralista, sino que deberán anclarse en una ética que sustente las interacciones sociales. Pero ¿cuál es esta ética? Para salvar todo tipo de conflictos deberán existir mínimos éticos, en el sentido de tener un piso de principios compartidos, a modo de expectativas, para llegar a una mesa o espacio de conversación o negociación. Estos mínimos no serán garantía de una solución mágica, pero serán el andamiaje en una sociedad que privilegia el conflicto y el desacuerdo, es decir, principios básicos que fungirían como marcos normativos y que deberían servir como plataforma para ponernos de acuerdo ante los conflictos que se manifiestan en la sociedad. Es por eso que se hace necesario, entre los actores afectados por las externalidades negativas que nos trae el desarrollo -que ya no son próximos sino mundiales -, sentarse a una mesa a negociar voluntariamente soluciones y acuerdos pertinentes y austeros para salvar las diferencias. Esto será posible, si asumimos la responsabilidad que implica hacernos cargo de nuestros espacios y proyectar territorios democráticos, inclusivos y donde sus actores sean vitales en el desarrollo de las generaciones presentes y futuras.

(Recebido para publicação em dezembro de 2008) (Aceito em março de 2009)

\section{REFERÊNCIAS}

BECK, U. La invención de lo político. Para una teoría de la modernización reflexiva, Buenos Aires: FCE, 1999. p.267.

CORTINA, A. Ética aplicada y democracia radical. Madrid: Tecnos, 1993. p. 288.
Ética mínima. Introducción a la filosofía práctica. Madrid: Tecnos, 1986. p.304.

La ética para la sociedad civil. Madrid: Anaya, 1994. p. 152

FISAS, V. Cultura de paz y gestión de conflictos. Barcelona: Icaria, Antrazyt/UNESCO, 2001. p.412.

HABERMAS, J. Aclaraciones a la ética del discurso. Madrid: Trotta, 2000. p.240.

HOYOS, G. Herramientas filosóficas de conocimiento par la comprensión y el manejo de conflictos. Bogotá: Universidad Nacional de Colombia, s/f. 8 f. (mimeo)

INNERARITY, D. El nuevo espacio público. Madrid: Espasa Calpe, 2006.

La transformación de la política. Barcelona: Ediciones Península, 2003.

Pluralismo Trágico. La organización política del desacuerdo. Debats, Valencia,ES, n.60, p.11-23, 1997.

LECHNER, R. Tres formas de coordinación social. Revista de la Cepal, Santiago do Chile, n.61, p.7-17, 1997.

LUHMANN, N. La sociedad de la sociedad, México,DF: Herder; Universidad Iberoamericana, 2007. p.964.

MARTINEZ GUZMAN, V. Saber Hacer las Paces. Epistemología de los estudios para la paz. Convergencia: revista de ciencias sociales, México,DF, n.23, p.49-96, 2000 .

p.209.

Teoría de la paz. Valencia: Nau llibres, 1995.

MASCAREÑO, A. Teoría de Sistemas en América Latina: conceptos fundamentales para la descripción de una diferenciación social concéntrica. Revista Persona y Sociedad, La Rioja,ES, v.16, n.2, p.9-26, 2001.

Diferenciación Funcional en América Latina: los contornos de una sociedad concéntrica y los dilemas de su transformación. Persona y Sociedad, La Rioja,Es, v.14, n.1, abr., p.187-207, 2000.

MASCAREÑO, A.: MEREMINSKAYA, E. Hacia la consolidación de la equidad: un defensor del pueblo para Chile. Santiago do Chile: Universidad Alberto Hurtado, 2005. (Colección de investigaciones jurídicas)

MAYNTZ, R. El Estado y la sociedad civil en la gobernanza moderna. Reforma y Democracia, Caracas, n.21, oct., p.722, 2001.

NEVES, M. De la autopoiésis a la alopoiésis del derecho. Revista Doxa, Madri, n.19, p.403-420, 2000.

A constitucionalização simbólica. São Paulo: Nova Acadêmica, 1994. p.288.

Del pluralismo jurídico a la miscelánea social: el problema de la falta de identidad de la(s) esfera(s) de juridicidad en la modernidad periférica y sus implicaciones en América Latina. En: ENCUENTRO INTERNACIONAL DE DERECHO ALTERNATIVO, 2. Florianópolis. Santa Catarina: 29 de septiembre al 2 de octubre de 1993.

SARTORI, G. Fundamentos del pluralismo. Leviatán: revista de hechos e ideas, [S.l.], n.61, p.111-126, 1995.

STICHWEH, R. Zur Theorie der Weltgesellschaft. In: Die Weltgesellschaft. soziologische analicen. Frankfurt am Main: Suhrkamp Verlag, 2000. p.7-27.

TAYLOR, CH. El Multiculturalismo y la política del reconocimiento. México,DF: FCE, 1993. p.160.

TEUBNER, G.; GÓMEZ-JARA DÍEZ, C. El Derecho como sistema autopoiético de la sociedad global. Bogotá: Universidad Externado de Colombia, 2005. p.134. 
VALLEJOS, A. Conflictos socioambientales en la periferia de la modernidad. Apuntes para la intervención en contextos locales. Revista de Ciencias Sociales, Maracaibo,VE, v.14, n.2, p.240-254, mayo/ago., 2008.

La política en la periferia de la modernidad.

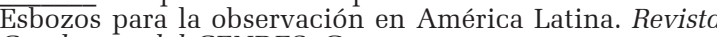
Cuadernos del CENDES, Caracas, n.65, p.95-128, mayo/ ago., 2007.

Políticas públicas, gobiernos locales y resolución de conflictos. Cuando en la toma de decisiones "muchos es mejor que pocos. Imaginales, Revista de Investigación Social, México,DF, v.3, n.6, p.47-56, 2007.

Los Conflictos Ambientales en una Sociedad Mundializada. Algunos antecedentes y consideraciones para Chile. Revista LIDER Segunda Época, Osorno,CH, p.193-214, 2005 .
WILLKE, H. La transformación de la democracia como modelo de orientación de las sociedades complejas. Estudios Públicos, [S.l.], n.102, p.179-201, 2006

ZAMORANO, R. Civilizzazione delle aspettative e democrazia nella periferia della società moderna. Leche: Pensa Multimedia Editore, 2003a, p. 192.

. Diferenciación y desdiferenciación política en la modernidad y periferia de la sociedad moderna. Revista Economía, Sociedad y Territorio, Mexico,DF, v.13, n.13, p.63-93, 2003b. 


\section{CONFLITIVITY AND MODERNITY: an minimalist ethics for conflict resolution}

\section{Arturo Vallejos Romero}

The objective of this paper is to confront some ideas that can help us to save the disagreements in pluralist societies, conflictive and complex like Latin America itself. Specifically, the ideas that will be exposed and confronted in the text will begin with a brief introduction, and, afterwards, with an exposition of the pluralism in our current societies and how this impels us to look for viable exits to save our differences. Later, we will discuss the kind of consensus that we should assume and the dialogue option or communicative pact to obtain it. We will take, for the previous topic, some concepts of communicative action and a discursive ethics, to then approach the structure in which certain desirable minimal denominators would be sustained to account for dissension and (or) conflict, and the proposal of some minimal denominators. Consequently, we will talk about the State role as a warranty of the commonwealth, for, finally, to sketch some conclusions.

KEYWORDS: conflict resolution, communication, pluralism, dialogue, differentiation.
CONFLICTUALITÉ ET MODERNITÉ: une étique de minima pour résoudre les conflits

\section{Arturo Vallejos Romero}

L'objectif de cet article est de confronter certaines idées capables de nous aider à sauver les mésententes dans les sociétés pluralistes, conflictuelles et complexes comme en Amérique Latine. Plus précisément, après une brève introduction pour présenter et confronter les idées, le texte présentera le pluralisme dans les sociétés actuelles afin de nous obliger à rechercher des solutions viables capables de sauver nos différences. Ensuite, nous parlerons du type de consensus que nous devrions assumer et du choix des dialogues ou pactes communicatifs pour y arriver. Quelques concepts d'actions communicative et d'éthique discursive seront adoptés pour cela afin d'aborder la structure dans laquelle quelques minima désirables devront être maintenus pour rendre compte des dissensions et (ou) conflits, et en arriver à la proposition de quelques minima. Par conséquent, le discours portera sur le rôle de l'Etat en tant que garantie du bien commun pour ébaucher enfin quelques conclusions.

MOTS-CLÉS: solution de conflits, communication, pluralisme, dialogue, différenciation.

Orlando Arturo Vallejos Romero - Doutor em Ciências Sociais. Professor do Centro de Estudos de Desenvolvimento Local e Regional (CEDER) da Universidade de Los Lagos. Integra o Núcleo de Pesquisa Economia e Meio Ambiente do CEDER, desenvolvendo pesquisas na área de Sociologia Ambiental, Sociologia do Risco, Intervenção Ambiental e Conflitos Socioambientais. Suas mais recentes publicações são: Artigos: Políticas Públicas, Gobiernos Locales y Resolución de Conflictos. Cuando en la toma de decisiones "muchos es mejor que pocos", Imaginales, Revista de Investigación Social (Latindex, Redalyc), Universidad de Sonora, v. 3, n. 6, 2008; Conflictos Socioambientales en la periferia de la Modernidad. Apuntes para la intervención en contextos locales. Revista de Ciencias Sociales (ISI), v. 14, n. 2, Mayo-Agosto de 2008, Venezuela. Libros: Czerny, Miroslawa; Vallejos, Arturo; Park, James (Comp.) (2009), Territorio y desarrollo: dilemas de la modernidad en regiones, CEDER. Universidad de Los Lagos/Universidad de Varsovia, Osorno, Chile. 
